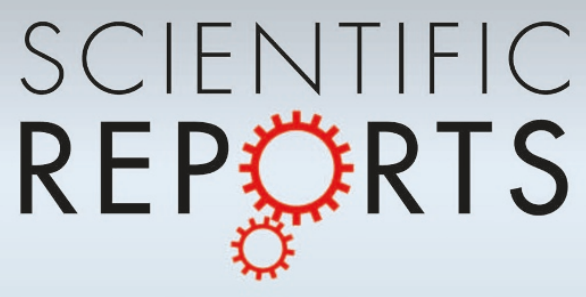

OPEN

SUBJECT AREAS:

ATMOSPHERIC

CHEMISTRY

PLANT SIGNALLING

ECOSYSTEM SERVICES

ENVIRONMENTAL MONITORING

Received

26 June 2013

Accepted

28 August 2013

Published

3 October 2013

Correspondence and requests for materials should be addressed to T.A.N. (tan@soton.ac.

* These authors contributed equally to this work.

\section{Diesel exhaust rapidly degrades floral odours used by honeybees}

\author{
Robbie D. Girling * , Inka Lusebrink ${ }^{*}$, Emily Farthing' ${ }^{1}$ Tracey A. Newman² \& Guy M. Poppy ${ }^{1}$
}

${ }^{1}$ Centre for Biological Sciences, Institute for Life Sciences, University of Southampton, Southampton SO 17 1BJ, UK, ${ }^{2}$ CES, Faculty of Medicine, Institute for Life Sciences, University of Southampton, Southampton SO17 1BJ, UK.

Honeybees utilise floral odours when foraging for flowers; we investigated whether diesel exhaust pollution could interrupt these floral odour stimuli. A synthetic blend of eight floral chemicals, identified from oilseed rape, was exposed to diesel exhaust pollution. Within one minute of exposure the abundances of four of the chemicals were significantly lowered, with two components rendered undetectable. Honeybees were trained to recognise the full synthetic odour mix; altering the blend, by removing the two chemicals rendered undetectable, significantly reduced the ability of the trained honeybees to recognize the altered odour. Furthermore, we found that at environmentally relevant levels the mono-nitrogen oxide $\left(\mathrm{NO}_{\mathrm{x}}\right)$ fraction of the exhaust gases was a key facilitator of this odour degradation. Such changes in recognition may impact upon a honeybee's foraging efficiency and therefore the pollination services that they provide.

C

hemical odours are central to communication in insects and their interaction with the environment ${ }^{1}$. A prime example of this is the floral odours that are produced by flowering plants to manipulate the behaviour of insects and facilitate pollination ${ }^{2,3}$. Globally the economic value of pollination has been estimated at $€ 153$ billion a year ${ }^{4}$, with $70 \%$ of the world's principal food crops relying upon pollination, equating to $35 \%$ of global food production ${ }^{5}$. Pollinator populations are declining on a global scale ${ }^{6}$ and anthropogenic substances, such as synthetic insecticides, are implicated as key contributors to the reductions of both wild ${ }^{7,8}$ and managed pollinators ${ }^{9-11}$.

Honeybees (Apis mellifera) are our most significant managed pollinator, yet every year significant numbers of honeybee colonies unexpectedly die worldwide ${ }^{6,9}$. The declines in managed honeybee populations have led to calls for further research to be conducted to enhance our understanding of honeybee health and well-being ${ }^{12}$. Current theory indicates that losses are most likely due to a combination/interaction of multiple factors ${ }^{9,10}$. However, whilst our comprehension of how these factors impact directly upon honeybee health is advancing, additional as yet undiscovered mechanisms are likely to be involved in honeybee declines.

Air pollution is one of the most ubiquitous environmental human impacts ${ }^{13}$, however its effects on honeybees are unknown. Honeybees have a sensitive sense of smell and an exceptional ability to learn and memorize new odours, enabling them to use floral odours to help locate, identify and recognise the flowers from which they forage $e^{14}$. There is a huge diversity of floral odours ${ }^{15}$, therefore any disruption to these blends could impact upon the ability of plants to communicate with their pollinators, which may have a negative impact on both parties. Theoretical models predict that anthropogenic emissions (including ozone, hydroxyl radicals and nitrate radicals) are likely to reduce the detection distances of plant emitted odours available to pollinators ${ }^{16}$, and empirical data has demonstrated that such compounds can interrupt plant-to-plant odour communication ${ }^{17}$.

Despite advances in filtration technology and tighter regulations on airborne emissions ${ }^{13}$, diesel exhaust remains a major environmental pollutan $t^{18}$. Many countries have guidelines in place to limit the emission of toxic gases produced as a result of the combustion of diesel and other fossil fuels (Table 1$)^{13}$. Of these gases the $\mathrm{NO}_{\mathrm{x}}$ fraction is the most reactive and is known to have deleterious effects on both human health ${ }^{19}$ and plant growth $^{20}$. However the emissions limits for one of the $\mathrm{NO}_{\mathrm{x}}$ gases, nitrogen dioxide, are regularly exceeded especially in urban areas ${ }^{21}$. Whilst there is an overall downward trend in nitrogen dioxide emission in Europe $^{21}$, it continues to be a significant environmental pollutant, particularly in countries undergoing rapid economic growth, such as China ${ }^{22}$.

We investigated whether diesel exhaust pollution alters the constituents of a synthetic floral odour blend, and if the highly reactive gases at concentrations down to environmentally relevant levels (100 ppb NO, $10 \mathrm{ppb} \mathrm{NO}_{2}$ ) were responsible for such changes and whether the changes elicited by this interaction could impair honeybee recognition of the floral blend. 
Table $1 \mid$ Ambient air quality standards for the major pollutant gases in diesel exhaust

\begin{tabular}{|c|c|c|c|c|c|}
\hline & \multicolumn{2}{|c|}{ EU ambient air quality standards ${ }^{1}$} & \multicolumn{2}{|c|}{ US ambient air quality standards ${ }^{2}$} & $\begin{array}{l}\text { Average maximum values used } \\
\text { in diesel exposure experiments }\end{array}$ \\
\hline & Averaging period & $\begin{array}{l}\text { Concentration } \\
\text { (abundance) }\end{array}$ & Averaging period & $\begin{array}{l}\text { Concentration } \\
\text { (abundance) }\end{array}$ & Concentration (abundance) \\
\hline \multirow[t]{2}{*}{ Nitrogen dioxide $\left(\mathrm{NO}_{2}\right)$} & 1 hour & $\begin{array}{l}200 \mu \mathrm{g} / \mathrm{m}^{3} \\
(100 \mathrm{ppb})\end{array}$ & 1 hour & $\begin{array}{l}200 \mu \mathrm{g} / \mathrm{m}^{3} \\
(100 \mathrm{ppb})\end{array}$ & $\begin{array}{l}35.5 \mathrm{mg} / \mathrm{m}^{3} \\
(17.5 \mathrm{ppm})\end{array}$ \\
\hline & 1 year & $\begin{array}{l}40 \mu \mathrm{g} / \mathrm{m}^{3} \\
(20 \mathrm{ppb})\end{array}$ & 1 year & $\begin{array}{l}107 \mu \mathrm{g} / \mathrm{m}^{3} \\
(53 \mathrm{ppb})\end{array}$ & \\
\hline \multirow[t]{2}{*}{ Carbon monoxide (CO) } & 8 hour & $\begin{array}{l}10 \mathrm{mg} / \mathrm{m}^{3} \\
(8 \mathrm{ppm})\end{array}$ & & $\begin{array}{l}43 \mathrm{mg} / \mathrm{m}^{3} \\
(35 \mathrm{ppm})\end{array}$ & $\begin{array}{l}280 \mathrm{mg} / \mathrm{m}^{3} \\
(227 \mathrm{ppm})\end{array}$ \\
\hline & & & 8 hour & $\begin{array}{l}11 \mathrm{mg} / \mathrm{m}^{3} \\
(9 \mathrm{ppm})\end{array}$ & \\
\hline Sulphur dioxide $\left(\mathrm{SO}_{2}\right)$ & & $\begin{array}{l}350 \mu \mathrm{g} / \mathrm{m}^{3} \\
(125 \mathrm{ppb})\end{array}$ & 1 hour & $\begin{array}{c}212 \mu \mathrm{g} / \mathrm{m}^{3} \\
(75 \mathrm{ppb})\end{array}$ & None detected \\
\hline
\end{tabular}

\section{Results}

Floral odour analysis - diesel exposures. The natural floral odour from oilseed rape flowers (Brassica napus) (Fig. 1a) comprises a complex mix of chemicals. Our synthetic odour blend consisted of the 8 chemicals from this mix that elicit the strongest behavioural responses from honeybees ${ }^{23}$. The proportion of each chemical in our blend was designed to mimic the ratio at which they are naturally emitted from rape flowers (Fig. $1 \mathrm{~b}$ and Supplementary Table 1). The blend was released into a sealed glass vessel that contained either ambient 'clean' air or air mixed with diesel exhaust. The volatile abundance of each chemical was then measured using gas chromatography-mass spectrometry (Supplementary Fig. 1). These diesel exhaust treatments contained high concentrations of $\mathrm{NO}_{\mathrm{x}}$ (nitric oxide and nitrogen dioxide) and carbon monoxide, however no sulphur dioxide was present (Table 1).

Within one minute $\alpha$-farnesene and $\alpha$-terpinene, which respectively constituted $72.5 \%$ and $0.8 \%$ of the original odour blend (Fig. 1b), were rendered undetectable in diesel polluted air and remained undetectable for the 2 hour study period (Fig. 1e, i \& $\mathrm{k}$ and Supplementary Table 2). At every time point, two of the remaining six chemicals' volatile abundances were significantly reduced by diesel exhaust compared with ambient air. Counter intuitively, the abundance of $p$-cymene was significantly increased by diesel exhaust after 60 minutes (Fig. If and Supplementary Table 3). All eight chemicals remained detectable after 2 hours in ambient air, indicating their relative stability in the absence of diesel exhaust and standard errors were tight across all time points demonstrating the consistency of the responses. Chemical abundances were often lowest at one minute, this was most pronounced amongst those chemicals that have lowest vapour pressures and therefore vaporize more slowly (Fig. 1g-j and Supplementary Table 1).

Floral odour analysis - $\mathrm{NO}_{\mathrm{x}}$ exposures. The $\mathrm{NO}_{\mathrm{x}}$ and diesel experiments were carried out using an identical design, except that instead of exhaust gases the glass vessel was filled with a combination of nitric oxide and nitrogen dioxide at two different ratios and at a range of different concentrations. The highest dose of $\mathrm{NO}_{\mathrm{x}}$ gases was to produce a worst case scenario, i.e. to replicate the concentrations and ratios measured in the diesel exhaust gas experiments. In order to investigate the relative impact of $\mathrm{NO}$ (which undergoes conversion to $\mathrm{NO}_{2}$ under normal atmospheric conditions) the ratio of gases was skewed as far as possible to an NO enriched mixture. The range of doses were selected to range from those levels found in the diesel exhaust exposed sample, down to levels that are in line with the maximum recommended airborne levels under the current health guidance. In a $1: 1$ ratio at $10 \mathrm{ppm}$ of each gas, approximately half the concentration used in the diesel exposure experiment, $\alpha$-terpinene was rendered undetectable, $\alpha$-farnesene was reduced by $97 \%$ and phenylacetaldehyde by $90 \%$ (Fig. 2, Supplementary Figs. 2-9 and Supplementary Table 5). Furthermore, in the $1: 1$ ratio at $0.1 \mathrm{ppm}$ (i.e. $100 \mathrm{ppb}$ ), which is equivalent to the hourly average of nitrogen dioxide levels permitted by both EU and US air quality standards (Table 1), there were significant reductions in four of the eight components of the odour blend. Unexpectedly, exposure to $\mathrm{NO}_{\mathrm{x}}$ resulted in relative increases in the mean abundances of $\alpha$-pinene, 3-carene and p-cymene (Fig. 2 and Supplementary Figs. 2, 3 and 5).

Proboscis extension reflex (PER). We used the proboscis extension reflex of honeybees, where a honeybee extends its proboscis (Fig. 3bc) when its antennae come into contact with sugar solution ${ }^{24}$, to train forager honeybees to associatively learn the synthetic floral odour blend. Trained honeybees should extend their proboscis when they next recognize the odour blend in the absence of reward. Honeybees were then presented with either the synthetic odour blend, or one of three artificially manipulated blends from which either $\alpha$-farnesene, $\alpha$-terpinene or both chemicals were omitted.

Removal of $\alpha$-farnesene, the major component in the synthetic odour blend, did not significantly reduce recognition relative to the full blend (Fig. 3d). In contrast, removal of $\alpha$-terpinene, a very minor component $(0.8 \%)$ of the blend (Fig. $1 \mathrm{~b}$ and Supplementary Table 1 ), significantly reduced recognition and when both chemicals were removed recognition dropped further.

\section{Discussion}

Honeybee pollination can significantly increase the yield of crops, as typified by oilseed rape (Fig. $3 a)^{26,27}$ however, to forage effectively, honeybees need to be capable of learning and recognizing the plants floral odour blend ${ }^{2,28}$. Our results infer that a constituent of airborne pollutants, $\mathrm{NO}_{\mathrm{x}}$ gases, may be capable of disrupting the odour recognition process that odour guided pollinating insects rely on for location of floral food resources. Our experiments utilised higher total concentrations of $\mathrm{NO}_{\mathrm{x}}$ in the $1: 1$ than the $10: 1$ ratio experiments, because in producing the two different ratios the nitric oxide concentrations were kept constant, despite this the $1: 1$ ratio resulted in the greater reductions in abundances (Fig. 2 and Supplementary Tables 4 and 5), inferring that nitrogen dioxide may be more 


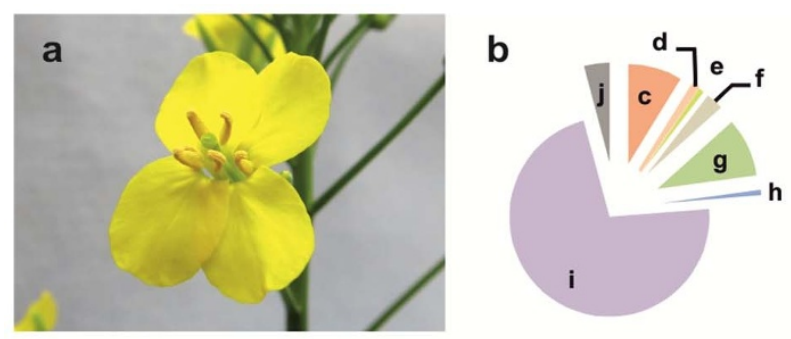

involved than nitric oxide in the odour degradation process. As may be anticipated in a chemically reactive environment, one component of the blend, $p$-cymene, was detected at higher levels after $\mathrm{NO}_{\mathrm{x}}$ exposure. This may be as a product of the known reaction between $\alpha$-terpinene and nitrates ${ }^{25}$.

Honeybees are known to use the whole range of chemicals found in a floral blend to discriminate between different blends ${ }^{29}$, our results indicate that some chemicals in a blend may be more important than others in this discrimination process. Whilst these results are the outcome of an artificial manipulation of the odour blend, the fact that removal of such a minor constituent can have such a profound effect on the ability of honeybees to recognize a floral odour may have significant ramifications for the ability of honeybees to efficiently forage for floral resources and therefore provide pollination services.

In nature honeybees use a combination of visual stimuli ${ }^{28}$ and floral odours ${ }^{2}$ to locate a flower for the first time. Honeybees associatively learn that a floral odour is concomitant with foraging success by gaining a reward of nectar whilst on the flower in the presence of high levels of floral odours ${ }^{24}$. Learning a floral odour remotely from the flower is less likely, because it would require a honeybee to remember an odour that occurs at a time distinct from the reward. Degradation of an odour source by pollution is likely to be more pronounced at distance from the flower, where concentrations of the odours are lower. Foraging honeybees may then be incapable of recognizing that the floral odours it detects remote from flowers are those that it associates with reward. This could result in a greater dependence upon other senses critical for foraging behaviour, such as vision, to compensate for the reduction in olfactory stimuli.

Disruption of odour communication by components of exhaust pollution could be detrimental to many insect species. In the case of pollinator species, including the honeybee, these effects would have major economic and ecological impacts, particularly when in conjunction with other stressors detrimental to pollinator health.

\section{Methods}

Floral odour collections. Floral odour collections were made in cleaned 1 litre amber borosilicate glass bottles (VWR). For the diesel exhaust experiment, bottles were filled with either ambient air or diesel exhaust, collected at $1 \mathrm{l} \mathrm{min}^{-1}$ for $3 \mathrm{~min}$ from a diesel generator's exhaust (Suntom SDE 6500 E; Fuzhou). The diesel generator was run using a standard operating protocol of warm-up, engine load and time to first collection; the fuel and the engine oil were consistently purchased from the same supplier. The generator was maintained according to the manufacturers instructions. The concentrations of nitrogen dioxide $\left(\mathrm{NO}_{2}\right)$, nitric oxide $(\mathrm{NO})$, carbon monoxide $(\mathrm{CO})$ and sulphur dioxide $\left(\mathrm{SO}_{2}\right)$ produced at the generator's exhaust were measured using a toxic gas probe (TG501+; Graywolf Sensing Solutions). For the $\mathrm{NO}_{\mathrm{x}}$ experiments, $\mathrm{NO}_{\mathrm{x}}$ for the $10: 1 \mathrm{NO}: \mathrm{NO}_{2}$ ratio were produced from a commercially purchased gas cylinder (BOC Group) and for the $1: 1 \mathrm{NO}_{\mathrm{NO}_{2}}$ ratio $\mathrm{NO}_{\mathrm{x}}$ were produced by reducing nitric acid with elemental copper. Concentrations of $10 \mathrm{ppm}$, $1 \mathrm{ppm}, 0.1 \mathrm{ppm}$ per bottle were achieved by using gas tight syringes and volumetric calculations. Bottles were sealed with 2 layers of Parafilm ${ }^{\circledR}$ (Pechiney Plastic Packaging Company) and a GL45 cap (VWR). One microliter of the synthetic odour blend (Supplementary Table 1), applied to a $2.1 \mathrm{~cm}$ diameter filter paper (Grade $3 \mathrm{M}$ ), was placed into the glass bottle along with a stir bar (operated at $300 \mathrm{rpm}$ to mix air). After 1, 30, 60 and $120 \mathrm{~min}$ (only after $30 \mathrm{~min}$ for $\mathrm{NO}_{\mathrm{x}}$ experiments) of mixing a solid-phase microextraction fibre (SPME, blue fibre $65 \mu \mathrm{m}$ PDMS-DVB; Supelco) was inserted into the bottle through a $1 \mathrm{~mm}$ bore hole in the cap, for a $5 \mathrm{~min}$ exposure/adsorption period. For the diesel experiment, the process was repeated 5 times for both ambient air and diesel exhaust. For the $\mathrm{NO}_{\mathrm{x}}$ experiments, the process was repeated 4 times for ambient air and 4 times for each $\mathrm{NO}: \mathrm{NO}_{2}$ ratio and concentration. emitted from oilseed rape flowers. The colours and letters that represent each chemical are consistent throughout the figure. $(c-j)$, Mean volatile abundances ( \pm s.e.m) of the eight synthetic floral chemicals in ambient 'clean' air (darker lines) compared to their abundances in diesel exhaust polluted air (lighter lines) at four different times points after exposure ( $n=$ $5)$. (k), The changes in mean floral chemical abundance in diesel exhaust polluted air relative to ambient air; which were either statistically significant $(\mathbf{\nabla} ; \mathrm{P} \leq 0.05)$, or in the case of both $\alpha$-terpinene and $\alpha$-farnesene where the chemical was no longer detectable in diesel exhaust polluted air $(\boldsymbol{\nabla})$. Directions of arrowheads indicate either increases or reductions in relative abundance.

Floral odour analysis. Chemicals were thermally desorped from the SPME fibres in the injector $\left(250^{\circ} \mathrm{C}\right)$ of a Hewlett-Packard 6890 gas chromatograph, coupled to a 5972 mass spectrometer. The carrier gas was helium $\left(1 \mathrm{ml} \mathrm{min}^{-1}\right)$ and the injector was operated in a split mode $(10: 1)$. The capillary column was an HP-INNOWAX (30 m, $0.25 \mathrm{~mm}$ i.d., $0.25 \mathrm{~mm}$ film; Agilent Technologies). The oven temperature was held at $50^{\circ} \mathrm{C}$ for $2 \mathrm{~min}$ and then increased at $5^{\circ} \mathrm{C} \mathrm{min}^{-1}$ to $70^{\circ} \mathrm{C}$ and then at $10^{\circ} \mathrm{C} \mathrm{min}^{-1}$ to $240^{\circ} \mathrm{C}$. The mass spectrometer $\left(250^{\circ} \mathrm{C}\right)$ scanned from mass 350 to 40 at a rate of 2.43 times $\mathrm{s}^{-1}$ and data were captured and analysed by Enhanced Chemstation software (v. B.01.00; Agilent Technologies). The data for each chemical at each time point (or each $\mathrm{NO}_{\mathrm{x}}$ concentration and ratio) were examined for the normality of their distributions using a series of Shapiro-Wilk tests and normal Q-Q plots. For those time points that 


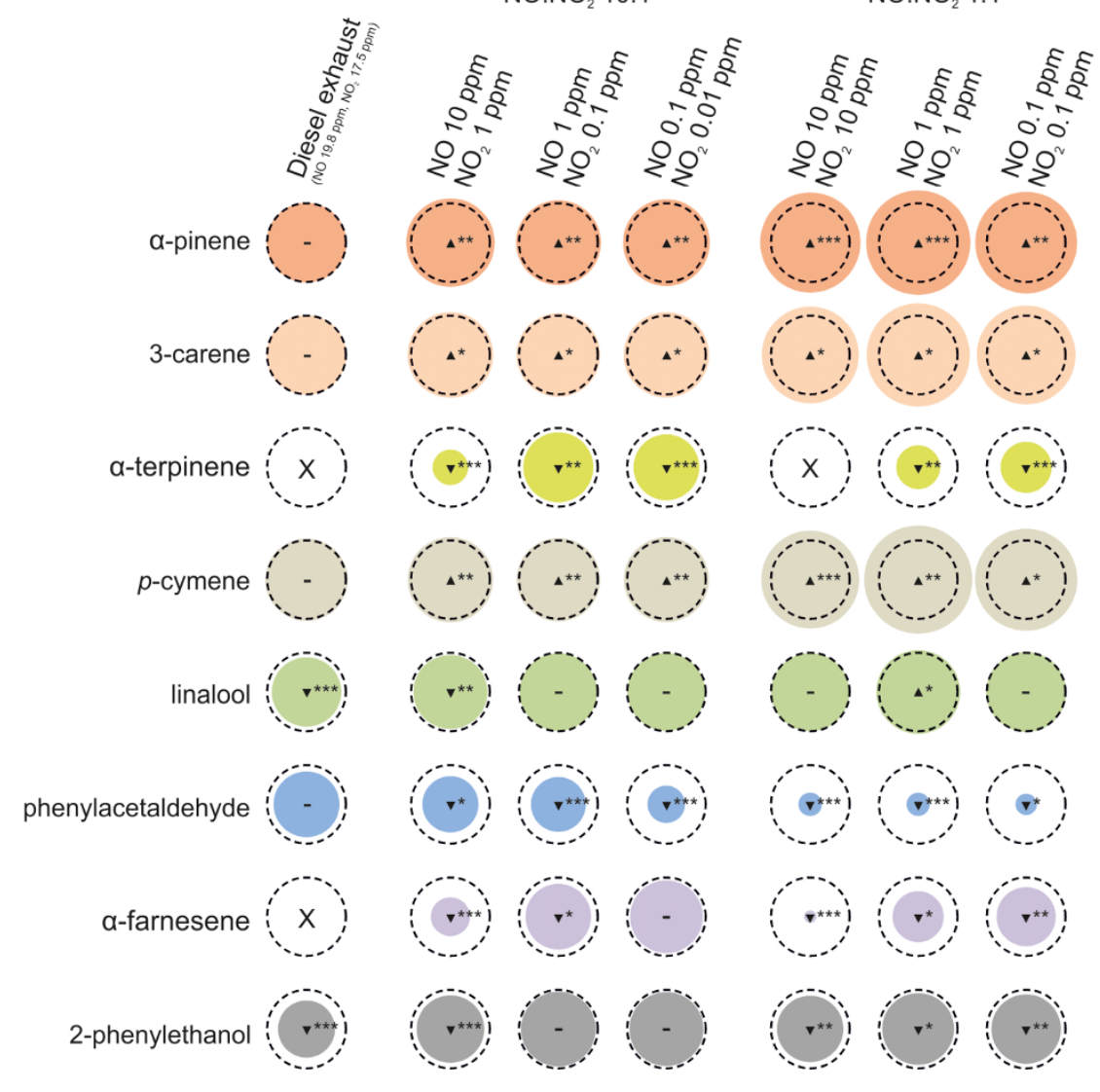

Figure $2 \mid$ The effects of varying concentrations and ratios of $\mathrm{NO}$ and $\mathrm{NO}_{2}$ upon the abundance of of a synthetic oilseed rape floral odour blend. Circles indicate the percent change in mean abundances of the synthetic floral chemicals in ambient 'clean' air (dashed circle) compared to their abundances in either diesel exhaust polluted air, or air contaminated with $\mathrm{NO}$ and $\mathrm{NO}_{2}$ (filled circles) at a ratio of $10: 1$ or $1: 1$, with $\mathrm{NO}$ at concentrations of 10,1 or $0.1 \mathrm{ppm}$ for both ratios $(n=4)$. Abundances were measured after 30 minutes. Statistically significant changes in abundance are denoted by an arrowhead that indicates a significant increase or decrease $\left(* \mathrm{P}<0.05,{ }^{*} \mathrm{P}<0.01,{ }^{* * *} \mathrm{P}<0.001\right)$. An $(\mathrm{X})$ indicates that the chemical was no longer detectable in those treatments.
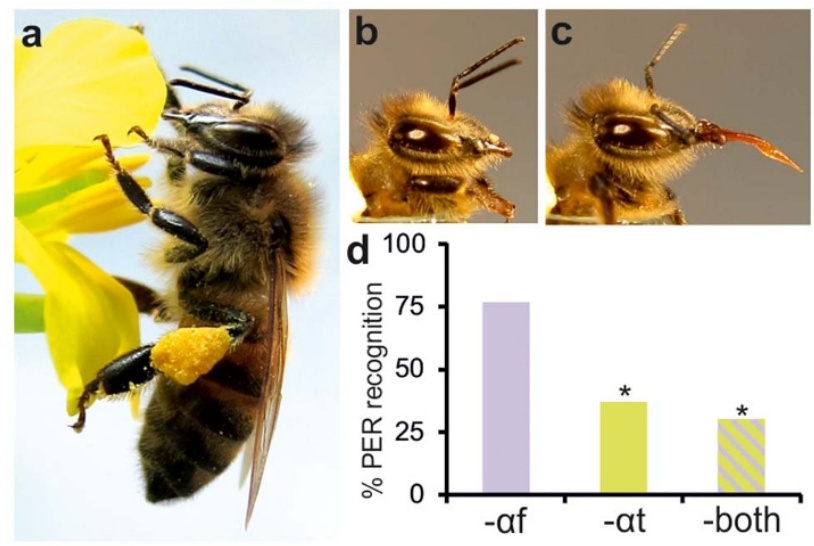

Figure 3 Tests of honeybee recognition of synthetic odour blends. (a), A honeybee worker foraging on an oilseed rape flower (photographs by $\mathrm{R}$ Girling, C Reitmayer). (b-c), A honeybee worker (photographs by R Girling, C Reitmayer) restrained for a proboscis extension reflex (PER) assay with proboscis retracted (b) and extended (c). (d), The percentage of forager honeybees which, after learning the full synthetic floral blend, extended their proboscis (indicating recognition) when presented with the synthetic blend minus either $\alpha$-farnesene $(-\alpha \mathrm{f}), \alpha$-terpinene $(-\alpha \mathrm{t})$ or both chemicals (-both). The data are expressed as the per cent PER recognition of each blend relative to the PER recognition of the full synthetic blend ( $n$ $\geq 25$ ), where on average $93 \%$ of forager honeybees learnt the full blend. Asterisks indicate a significant reduction in PER recognition of that blend in comparison to the full synthetic blend $(\mathrm{P}<0.05)$. were normally distributed, a series of unpaired two-tailed $t$-tests (SPSS v.19; IBM) were used to compare the mean abundances of each floral chemical between ambient air and diesel exhaust treatments. For each time point equal variances were assumed, unless Levene's tests demonstrated that variances were not equal. For those time points that were not normally distributed two-tailed Mann-Whitney U tests were performed (Supplementary Table 3).

Proboscis extension reflex (PER). Honeybees, Apis mellifera, were from colonies kept at the University apiary $\left(50^{\circ} 56^{\prime} 10^{\prime \prime} \mathrm{N}, 1^{\circ} 23^{\prime} 39^{\prime \prime} \mathrm{W}\right)$. For each assay, 30 returning forager honeybees (identified by full pollen baskets) were collected in individual plastic tubes between 14.00-16.00 BST. Honeybees were immobilized at $4{ }^{\circ} \mathrm{C}$, harnessed in $1 \mathrm{ml}$ pipette tips $\mathrm{s}^{30}$, fed to satiation with $30 \%$ sucrose solution and kept at $20^{\circ} \mathrm{C}$. The morning after collection, honeybees were randomly assigned into groups of 7-10 individuals. Each honeybee was trained to associatively learn the synthetic odour blend. A harnessed honeybee was placed in a well-ventilated chamber in front of a flow of ambient air. After $10 \mathrm{~s}$ the honeybee was exposed to odours from a glass tube containing a $2.1 \mathrm{~cm}$ diameter filter paper impregnated with $8 \mu \mathrm{l}$ of the synthetic blend, after a further $10 \mathrm{~s}$ the air flow was switched back to ambient. Five seconds into the odour stimulus the honeybees' antennae were touched with $30 \%$ sucrose solution and honeybees were allowed to feed for $10 \mathrm{~s}$. Each honeybee underwent 6 exposures with $10 \mathrm{~min}$ intervals between each exposure. Honeybees which extended their proboscis (Fig. 2c) in response to the odour stimuli on the 6th exposure were considered to have learnt the blend and were used in recognition trials. In the recognition trials the groups of honeybees were tested to one of four odours, either the synthetic blend or a blend where $\alpha$-farnesene, $\alpha$-terpinene or both chemicals were omitted. Recognition mirrored the conditioning trials, with the omission of sucrose. Extension of the proboscis within $10 \mathrm{~s}$ in response to the onset of the odour stimulus was classified as a positive recognition. Responses to each of the three manipulated blends are expressed as the per cent PER recognition of each blend relative to the per cent PER recognition of the full synthetic blend. A $\mathrm{X}^{2}$ test was used to compare the total numbers of honeybees recognizing each odour between all four odour groups, combined with a $z$-test to perform pairwise comparisons between odour groups (SPSS v.19; IBM). 
1. Cardé, R. T. \& Millar, J. G. Advances in Insect Chemical Ecology. (Cambridge University Press, 2004)

2. Raguso, R. A. Wake up and smell the roses: the ecology and evolution of floral scent. Annu. Rev. Ecol., Evol. Syst. 39, 549-569 (2008).

3. Dobson, H. E. M. in Insect-Plant Interactions (ed Bernays, E. A.) Vol. 5, 47-81 (CRC Press, 1994)

4. Gallai, N., Salles, J. M., Settele, J. \& Vaissiere, B. E. Economic valuation of the vulnerability of world agriculture confronted with pollinator decline. Ecol. Econ. 68, 810-821 (2009).

5. Klein, A. M. et al. Importance of pollinators in changing landscapes for world crops. Proc. R. Soc. B 274, 303-313 (2007).

6. Potts, S. G. et al. Global pollinator declines: trends, impacts and drivers. Trends Ecol. Evol. 25, 345-353 (2010).

7. Gill, R. J., Ramos-Rodriguez, O. \& Raine, N. E. Combined pesticide exposure severely affects individual- and colony-level traits in bees. Nature 491, 105-108 (2012).

8. Whitehorn, P. R., O'Connor, S., Wackers, F. L. \& Goulson, D. Neonicotinoid pesticide reduces bumble bee colony growth and queen production. Science 336 351-352 (2012).

9. Epstein, D. et al. USDA: Report on the national stakeholders conference on honey bee health. http://www.usda.gov/documents/ReportHoneyBeeHealth.pdf (2013). accessed March 2013.

10. Vanbergen, A. J. \& Initiative, T. I. P. Threats to an ecosystem service: pressures on pollinators. Front. Ecol. Environ. 11, 251-259 (2013).

11. Henry, M. et al. A common pesticide decreases foraging success and survival in honey bees. Science 336, 348-350 (2012)

12. Ratnieks, F. L. W. \& Carreck, N. L. Clarity on honey bee collapse? Science 327, 152-153 (2010).

13. WHO. Air Quality Guidelines for Particulate Matter, Ozone, Nitrogen Dioxide and Sulfur Dioxide. (WHO Press, 2006).

14. Chittka, L., Thomson, J. D. \& Waser, N. M. Flower constancy, insect psychology, and plant evolution. Naturwissenschaften 86, 361-377 (1999).

15. Knudsen, J. T., Eriksson, R., Gershenzon, J. \& Stahl, B. Diversity and distribution of floral scent. Bot. Rev. 72, 1-120 (2006).

16. McFrederick, Q. S., Kathilankal, J. C. \& Fuentes, J. D. Air pollution modifies floral scent trails. Atmos. Environ. 42, 2336-2348 (2008).

17. Blande, J. D., Holopainen, J. K. \& Li, T. Air pollution impedes plant-to-plant communication by volatiles. Ecol. Lett. 13, 1172-1181 (2010).

18. Benbrahim-Tallaa, L. et al. Carcinogenicity of diesel-engine and gasoline-engine exhausts and some nitroarenes. Lancet. Oncol. 13, 663-664 (2012).

19. Latza, U., Gerdes, S. \& Baur, X. Effects of nitrogen dioxide on human health Systematic review of experimental and epidemiological studies conducted between 2002 and 2006. Int. J. Hyg. Environ. Health 212, 271-287 (2009).

20. Bell, J. N. B., Honour, S. L. \& Power, S. A. Effects of vehicle exhaust emissions on urban wild plant species. Environ. Pollut. 159, 1984-1990 (2011).

21. Carslaw, D. et al. Trends in $\mathrm{NO}_{\mathrm{x}}$ and $\mathrm{NO}_{2}$ emissions and ambient measurements in the UK. http://uk-air.defra.gov.uk/reports/cat05/1108251149_110718 AQ0724_Final_report.pdf (UK, 2011). accessed July 2012.

22. Hill, S. Reforms for a cleaner, healthier environment in China. Report No.1045 OECD Publishing, http://dx.doi.org/10.1787/5k480c2dh6kf-en (2013). accessed April 2013
23. Blight, M. M. et al. Identification of floral volatiles involved in recognition of oilseed rape flowers, Brassica napus by honeybees. Apis mellifera. J. Chem. Ecol. 23, 1715-1727 (1997).

24. Bitterman, M. E., Menzel, R., Fietz, A. \& Schafer, S. Classical conditioning of proboscis extension in honeybees (Apis mellifera). J. Comp. Psychol. 97, 107-119 (1983).

25. Calogirou, A., Larsen, B. R. \& Kotzias, D. Gas-phase terpene oxidation products: a review. Atmos. Environ. 33, 1423-1439 (1999).

26. Sabbahi, R., De Oliveira, D. \& Marceau, J. Influence of honey bee (Hymenoptera: Apidae) density on the production of canola (Crucifera: Brassicacae). J. Econ. Entomol. 98, 367-372 (2005)

27. Bommarco, R., Marini, L. \& Vaissiere, B. E. Insect pollination enhances seed yield, quality, and market value in oilseed rape. Oecologia 169, 1025-1032 (2012).

28. Srinivasan, M. V. Honey bees as a model for vision, perception, and cognition. Annu. Rev. Entomol. 55, 267-284 (2010).

29. Wright, G. A., Lutmerding, A., Dudareva, N. \& Smith, B. H. Intensity and the ratios of compounds in the scent of snapdragon flowers affect scent discrimination by honeybees (Apis mellifera). J. Comp. Physiol., A 191, 105-114 (2005).

30. Felsenberg, J., Gehring, K. B., Antemann, V. \& Eisenhardt, D. Behavioural pharmacology in classical conditioning of the proboscis extension response in honeybees (Apis mellifera). J. Vis. Exp. e2282 (2011)

\section{Acknowledgments}

We thank C. Jackson and C. Reitmayer for their discussions on the project and for their help with beekeeping, and C.R. for taking the honeybee images used in figure 3. Funding for the project was provided by the Leverhulme Trust.

\section{Author contributions}

R.D.G., T.A.N. and G.M.P. conceived the study. I.L., R.D.G., T.A.N. and G.M.P. designed the experiments. I.L. performed the experiments and collected data for GC-MS studies. E.F. and I.L. performed the experiments and collected data for the PER tests. R.D.G. performed the analysis. R.D.G. and T.A.N. supervised data collection and wrote the manuscript. R.D.G and I.L. contributed equally to the study. All authors discussed the results and commented on the manuscript.

\section{Additional information}

Supplementary information accompanies this paper at http://www.nature.com/ scientificreports

Competing financial interests: The authors declare no competing financial interests.

How to cite this article: Girling, R.D., Lusebrink, I., Farthing, E., Newman, T.A. \& Poppy, G.M. Diesel exhaust rapidly degrades floral odours used by honeybees. Sci. Rep. 3, 2779; DOI:10.1038/srep02779 (2013)

(i) This work is licensed under a Creative Commons AttributionBY NG SA NonCommercial-ShareAlike 3.0 Unported license. To view a copy of this license, visit http://creativecommons.org/licenses/by-nc-sa/3.0 